\title{
Powder Characterization, Mixing Behaviour and Rheological Properties of Magnesium Powder Feedstock for Metal Injection Moulding Process
}

\author{
M. A. Omar ${ }^{1 *}$, N. Zainon ${ }^{2}$ \\ ${ }^{1}$ SIRIM Bhd, Lot 34, Jln Hi Tech 2/3, Kulim Hi Tech Park, 09000 Kulim, Kedah, Malaysia \\ ${ }^{2}$ School of Manufacturing Engineering, Univerisiti Malaysia Perlis, Kampus Pauh Putra, 02600 Arau, Perlis, Malaysia
}

\author{
DOI: $10.36348 /$ sjet.2020.v05i12.004 $\quad$ | Received: 26.11.2020 | Accepted: 08.12.2020 | Published: 18.12 .2020 \\ *Corresponding author: M. A. Omar
}

\section{Abstract}

Development of biodegradable metal implants is a complex problem because it combines engineering and medical requirements for a material. This paper discusses the development of magnesium powder using Metal Injection Moulding (MIM) techniques that can help in the design of biodegradable metallic implants. One of the most important factors in the process of biodegradable implants is to study the powder characterization, mixing behaviour and rheological properties of the powder/binder mixture, which should be monitored and controlled to address the medical concern of biocompatibility. Particle size analysis, scanning electron micrograph (SEM), thermogavimetric analysis (TGA) and differential scanning calorimeter (DSC) were performed in order to determine the characteristics of magnesium powder and binder components. The feedstock were prepared using powder loading of $0.61,0.63,0.65$ and 0.67 with binder formulations of $50 \% \mathrm{PW}-30 \% \mathrm{PP}-10 \% \mathrm{SA}-10 \%$. The flow properties were measured using a capillary rheometer in the shear rate range expected to occur during metal injection molding.

Keywords: Metal injection moulding, magnesium powder, particle size, mixing, rheology.

Copyright (C) 2020 The Author(s): This is an open-access article distributed under the terms of the Creative Commons Attribution 4.0 International License (CC BY-NC 4.0) which permits unrestricted use, distribution, and reproduction in any medium for non-commercial use provided the original author and source are credited.

\section{INTRODUCTION}

Magnesium (Mg) has high potential as a biomedical part. The critical advantage of $\mathrm{Mg}$ is its biodegradability. After a patient's injuries have healed, additional surgery for the removal of an implant could be avoided. Thus, both inconvenience and risk for the patient, as well as costs, can be reduced significantly. Standard implant materials such as titanium or stainless steel still suffer from stress shielding problems, causing bone desorption and 3 implant loosening. On the other hand, degradable polymers, such as polyglycolic acid (PGA) or polylactide acid (PLA), are less suitable for load bearing applications due to their inferior mechanical properties. In contrast, novel $\mathrm{Mg}-\mathrm{Ca}$ alloys show material properties matching those of cortical bone and are able to degrade fully into nontoxic elements essential for the human body [1, 2]. Nevertheless, biomedical magnesium alloy require appropriate mechanical properties, suitable degradation rate in physiological environment, and what is most important, biosafety to human body [3].

Metal Injection Moulding (MIM) possesses a high potential for the economic production of such implants. Moreover, the MIM processing route enables the establishment of both nearly dense as well as porous structures, helpful for tissue ingrowth into the degrading implant (Osseo integration). Interestingly, the density of $\mathrm{Mg}$ is slightly less than natural bone which ranges from 1.8 to $2.1 \mathrm{~g} / \mathrm{cm} 3$, while the elastic modulus of pure magnesium is $45 \mathrm{GPa}$ and human bone varies between 40 and $57 \mathrm{GPa}$ [3]. However, the conventional processing of magnesium is limited by multi manufacturing steps and their complexity contributes to significantly higher cost of the final product. The economy factor represents the downside of many nonconventional manufacturing techniques such as powder metallurgy. Thus, there is a continuous quest for a technology that would allow reducing cost and at the same time improving the properties application [8].

However, there is no significant study has been reported for the physical properties investigation on metal injection moulding (MIM) of $\mathrm{Mg}$ alloy powder for potential biomedical applications. The MIM process is composed of four sequential steps; mixing of the powder with organic binder, injection moulding, debinding (binder removal) and sintering $[4,5]$. In this study, preparation of the MIM feedstocks using $\mathrm{Mg}$ alloy powder has been investigated. Thereby, this study is focusing only on the powder characterization, mixing process, and preliminary study on rheological properties of the Mg feedstocks. 


\section{MATERIALS AND METHOD \\ Powder Characterization}

The magnesium gas stomised stainless steel powder were used in this study having a mean particle size of $22 \mu \mathrm{m}$. The mean particle size distribution was determined using a Coulter LS 130 Laser particle Size Analyser. In the current research work a paraffin wax (PW) based system was prepared. The ingredients with paraffin wax (PW) were Polypropylene (PE) and Stearic Acid (SA) $[6,7]$. The composition of the binder system was PW 70vol\%, PE 25vol\% and SA 5vol\%, minor components of the binder system acts as surface active agent. The binder system was thermally characterized by using TGA (Perkin Elmer).Testing was done under nitrogen atmosphere with heating rate of $20^{\circ} \mathrm{C} / \mathrm{min}$. The determination of the optimal powder loading using the Critical Powder Volume Concentration (CPVC) method. CPVC was estimated using Brabender Plastogram EC PLUS, manufactured by M-Brabender OHG Germany through oil absorption test and torque evolutions monitoring. The machine was equipped with a cam rotor which was used to compound both, the metal with the polymeric binder components and the neat binders.

The modified American Society Testing and Materials oil absorption test, ASTM D-281-12 can be used to determine the critical powder loading of a certain powder. 50 grams of powder mixed with $9 \mathrm{ml}$ of oleic acid in the mixer with $50 \mathrm{rpm}$ rotating speed at room temperature. After the mixture homogenized, $1 \mathrm{ml}$ of oleic acid added further and the mixture allowed becoming stable. After that $1 \mathrm{ml}$ of oleic acid keep added for every half an hour until it reaches the maximum torque and the changing torque recorded. The CPVP value was then determined according to the ratio of powder volume to the amount of oleic acid added and the powder volume. The CPVP value was then determined according to the ratio of powder volume to the amount of oleic acid added and the powder volume using Equation (1).

CPVP $=100 \times \frac{V_{f}}{\left(V_{f}+V_{o}\right)}$
Where,

$$
\begin{aligned}
V_{f} & =\text { volume of powder }\left(\mathrm{cm}^{3}\right) \\
& =\frac{\text { Actual weight of powder }(\mathrm{g})}{\text { Theoretical density of powder }\left(\mathrm{g} / \mathrm{cm}^{3}\right)} \\
V_{o} & =\text { volume of oleic acid }\left(\mathrm{cm}^{3}\right)
\end{aligned}
$$

\section{Mixing Process}

Mixing experiments were conducted in a Brabender Plastogram at $160^{\circ} \mathrm{C}$ and speed of $50 \mathrm{rpm}$ for 2 hours. When the required mixing temperature was reached, the binder with the composition shown in Table- 2 was loaded into the bowl little by little with the powder. The torque value is a measure of the resistance on the rotor blades. By observing the mixing torque values, the homogeneity of the feedstock prepared can be predicted: the lower the value, the better is the mix [7]. Uniform mixing was assumed to have occurred when the torque reached a steady state value.

\section{Rheological Properties}

After each mixing experiment, the feedstock viscosity was measured using a Shimadzu CFT-500D Capillary Rheometer. During the capillary rheometer test, the feedstock was forcibly extruded through a small cylindrical orifice with a $1.0 \mathrm{~mm}$ diameter and 10 $\mathrm{mm}$ length $(\mathrm{L} / \mathrm{D}=10)$. The palletized feedstocks were placed in the rheometer barrel and allowed to preheat for 120 s under $1,2,3,4$ and $5 \mathrm{MPa}$ test load before initiating testing. Then the piston will press the sample through the cylinder. Once the temperature of preheating sample was achieved, the air at the touch panel was press. The stopper was then removed and let the material flow through the die orifice.

\section{RESULTS AND DISCUSSION Powder Characterization}

Magnesium powder was obtained from $\mathrm{MGH}$ Industrial Co., Ltd, China. Fig-1 shows the morphology of magnesium powder. The SEM micrographs for the gas atomised powder demonstrate an approximately spherical shaped particles and a large proportion had smooth rounded surfaces as shown in Figure-1. The spherical shape aids the attainment of high packing density required for injection moulding. Moreover, German and Kubish [9] observed that the spherical powder tend to be easier to mould because of a low interparticle friction and a high packing density. Therefore, the tensile strength would increase greatly due to lower porosity. 


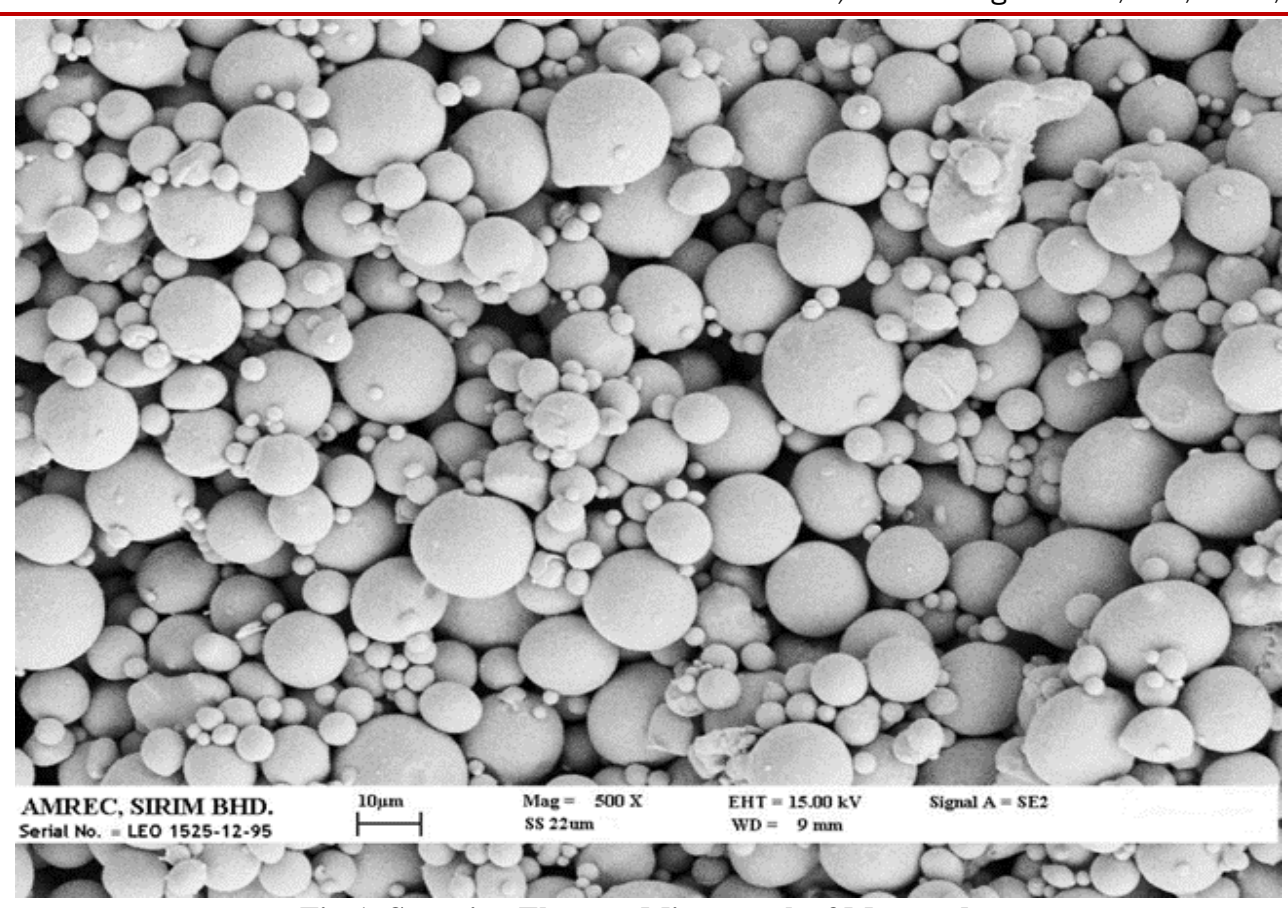

Fig-1: Scanning Electron Micrograph of Mg powder

The Particle Size Analyzer Model Coulter LS 130L used to determine the particle size of magnesium. The powder characteristics is tabulated in Table-1.

Table-1: Powder characterization of Magnesium powder

\begin{tabular}{|l|l|}
\hline Particle size & $\mathbf{D}_{\mathbf{5 0}}=\mathbf{2 2 . 4 5} \boldsymbol{\mu m}$ \\
\hline Pycnometer Density & $1.7338 \mathrm{~g} / \mathrm{cm}^{3}$ \\
\hline Particle shape & Spherical \\
\hline Width of particle size distribution, $\mathrm{S}_{\mathrm{w}}$ & 3.9666 \\
\hline Melting Point, $\mathrm{T}_{\mathrm{m}}$ & $650^{\circ} \mathrm{C}$ \\
\hline
\end{tabular}

\section{Determination of Critical Powder Loading}

Figure-2 represents the torque values and temperature corresponding to increasing additions of oleic acid. After adding $8 \mathrm{ml}$ of oleic acid at the beginning of the mixing, the temperature is increased from room temperature up to $31.7^{\circ} \mathrm{C}$. The addition of oleic acid cumulatively $9 \mathrm{ml}$, corresponded to the increasing temperature $32.3^{\circ} \mathrm{C}$.

The maximum temperature of $34{ }^{\circ} \mathrm{C}$ was reached when $10 \mathrm{ml}$ of oleic acid was added to the mixture. After that the temperature has no longer rise up on subsequent oleic acid addition, as there is no further decrease in friction energy. The mixing forces also begin to decrease since the excess oleic acid may cause the particles apart. The addition of $11 \mathrm{ml}$ to $13 \mathrm{ml}$ oleic acid will not increase the temperature since no longer friction in the mixing chamber.

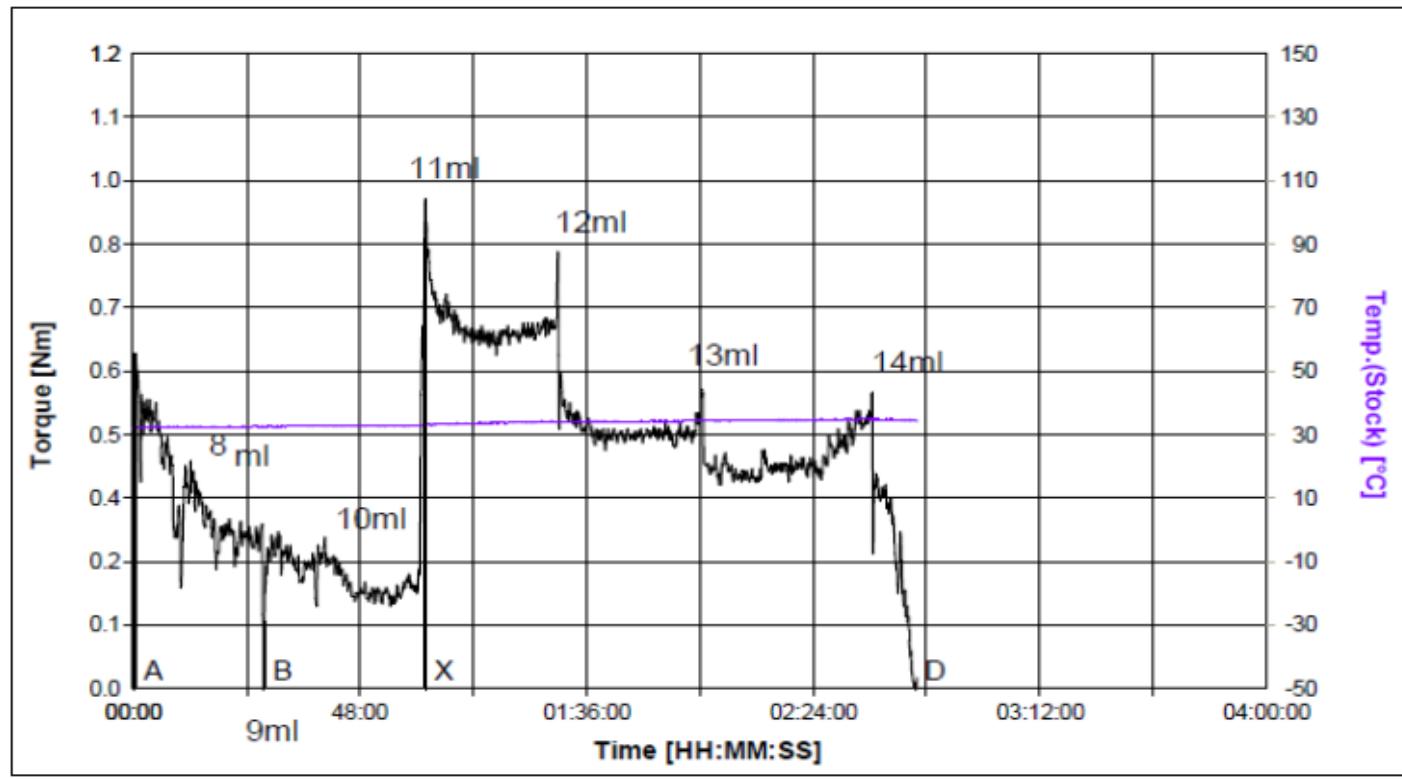

Fig-2: The torque values and temperature corresponding to increasing additions of oleic acid 
M. A. Omar \& N. Zainon; Saudi J Eng Technol, Dec, 2020; 5(12): 509-514

The CPVC was then calculated using equation 1 that gives CPVC value is 69 vol.\%. The result indicates that at 69 vol.\% of powder loading, the particles are tightly packed and the entire voids between particles are considered fully filled by the binder. German and Bose [5] determined that, 2 to $5 \%$ excessive of binder is necessary to reduce the friction in the mold during moulding.

\section{Binder Characterization using DSC}

The percentages of crystallization of the raw material used are reported in Table- 2 .

Table-2: Thermal properties of the raw materials involved as the binder system

\begin{tabular}{|r|r|r|r|}
\hline Material & Melt Temperature, $\mathbf{T}_{\mathbf{m}} \mathbf{( { } ^ { \mathbf { } } \mathbf { C } )}$ & Diffusion Heat, $\Delta \mathbf{H ~ ( J / g )}$ & Crystallization (\%) \\
\hline PW & 68.25 & 42.71 & 32.62 \\
\hline SA & 60.14 & 180.67 & 50.64 \\
\hline PE & 125.51 & 41.02 & 20.82 \\
\hline
\end{tabular}

The thermal analysis of DSC (Fig-3) is conducted to understand the viscosity behaviour of the binder and to select temperatures for kneading, moulding, solvent debinding and melting point The analysis is running over the raw materials involved as the binder system that is paraffin wax (PW) and stearic acid (SA).

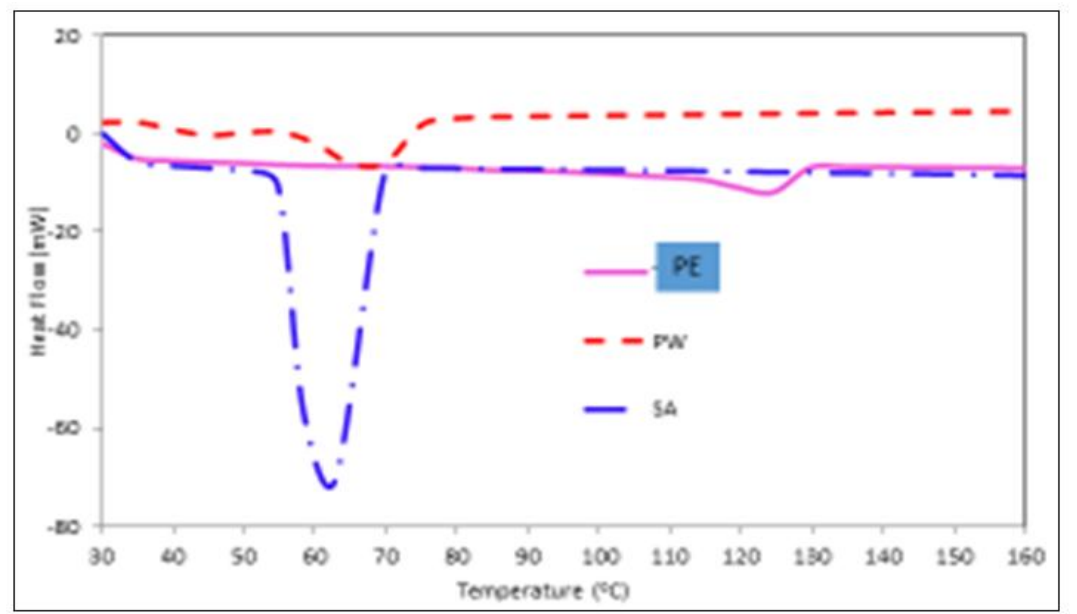

Fig-3: DSC thermogram of the PE, paraffin wax (PW), the lubricant, stearic acid (SA)

\section{Torque measurement at different powder loading}

The preparation of the feedstock is a very important step in MIM. The feedstock must be homogeneous enough to permit the filling of the mould during injection moulding. The main objective of this work is to analyse the mixing torque evolution based on the real data of torque which was generated during compounding. The concentration of powder had an important effect on the torque-evolution-curves as can be observed in Figure-4. Four powder loadings ranging from $60 \mathrm{vol} \%$ to $67 \mathrm{vol} \% \%$ of magnesium powder were evaluated by using the same formulation of binder system, 40 wt.\% PS and 60 wt.\% PE. It is generally desired that the feedstock should have the highest powder loading possible in order to obtain high green density and strength, and to minimize the subsequent sintering shrinkage.

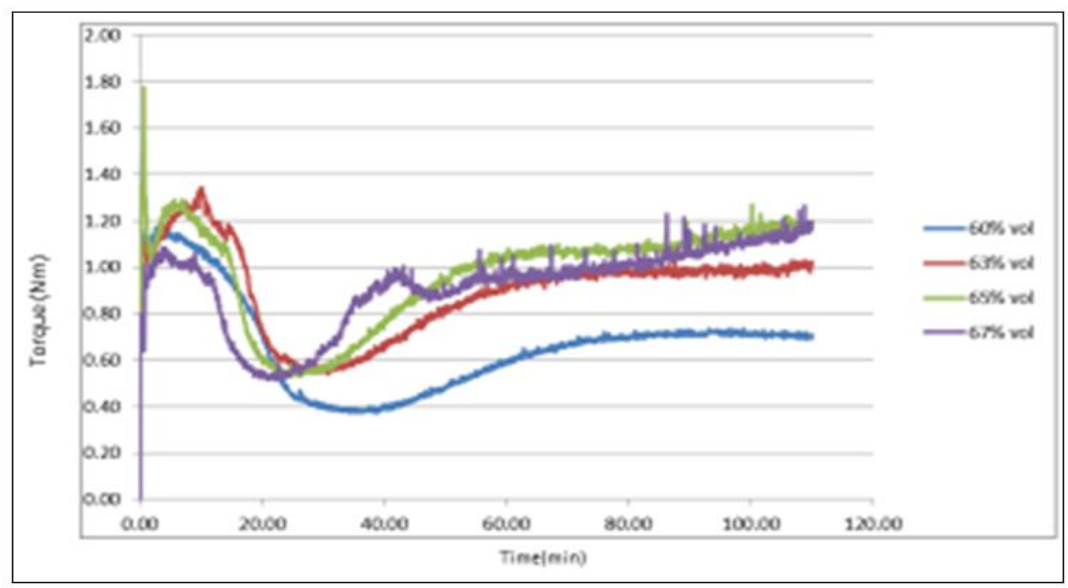

Fig-4: Torque evolution curve for Mg feedstock at different powder loading 
It shows the changes in torque as a function of mixing time. The mixing torque, proportional to the shear stress of the mixer indicates that the work energy is consumed to disperse and distribute the powder in the binder. The mixing time is defined as the time required for a mix to reach this steady state. It clearly shows that the torque value increases as the powder loading increases from 60 vol.\% to 65 vol.\%. This circumstance explains that greater friction occurred at the higher amount of powder loading that results in a higher viscosity of the mixture. For powder loading of the 65 vol.\% and 63 vol.\%, the torque stabilizes at a steady level in a short time, indicating a uniform mixing. As a contrast, the $60 \mathrm{vol} \%$ of powder loading took a longer time for the torque value to stabilize. This indicates that a homogeneous mixing is attained with a longer mixing time of 40 minutes.

However, when the loading increase to $65 \mathrm{vol} . \%$ to $67 \mathrm{vol} . \%$, it seems that the mixing torque is not stable. During mixing time, the torque keep fluctuate around $0.2 \mathrm{Nm}$. After 120 minutes mixing time, the curve still unstable and this indicates that the mixture is not uniform within the mixing time. This condition reflected to excessive content of powder that continuing consumed the energy for widely spread the powder in the binder during mixing. Moreover, the results also indicated that a longer mixing time is not necessary to attain a homogeneous mixture.

The feedstock with higher powder loading is required since the binder will be removed during debinding stage and to reduce the shrinkage on the final product after sintering process. The high powder loading has high tendency to void and agglomerate. The optimal powder loading is crucial for the metal injection moulding process. The results suggested that 65 vol.\% of $\mathrm{Mg}$ powder is the optimal powder loading for metal injection moulding.

\section{Rheological Characterization of the Feedstock}

Rheology study is compulsory in characterize the feedstock for matches the range of viscosities encountered in practice. The shear rates for moulding normally exceed the range obtainable with the rheometer. There are few studies involving the development of metal injection moulding process for magnesium powder. The rheological properties of the resulting feedstock were evaluated by the capillary rheometry. The effect of the relation of shear rate and temperature on viscosity for magnesium MIM feedstock has been investigated. The rheological results exhibited the pseudoplatic behavior.

Figure-5 shows the apparent viscosity versus shear rate of $\mathrm{Mg}$ MIM feedstock at different temperature for the powder loading of 65 vol. $\%$. The apparent viscosity of the Mg MIM feedstock was decreased with increasing of the shear rate. From the figure, the viscosity also observed to be sensitive with temperature. The apparent viscosity decreased with increasing temperature. This result indicates that the binder having the larger expansion when heat is introduced which causes the reduction in powder volume. Additionally, disentanglement of molecular chain when more heat is distributed to fluctuate the random molecular structure also reflects on sensitivity of the viscosity to the temperature.

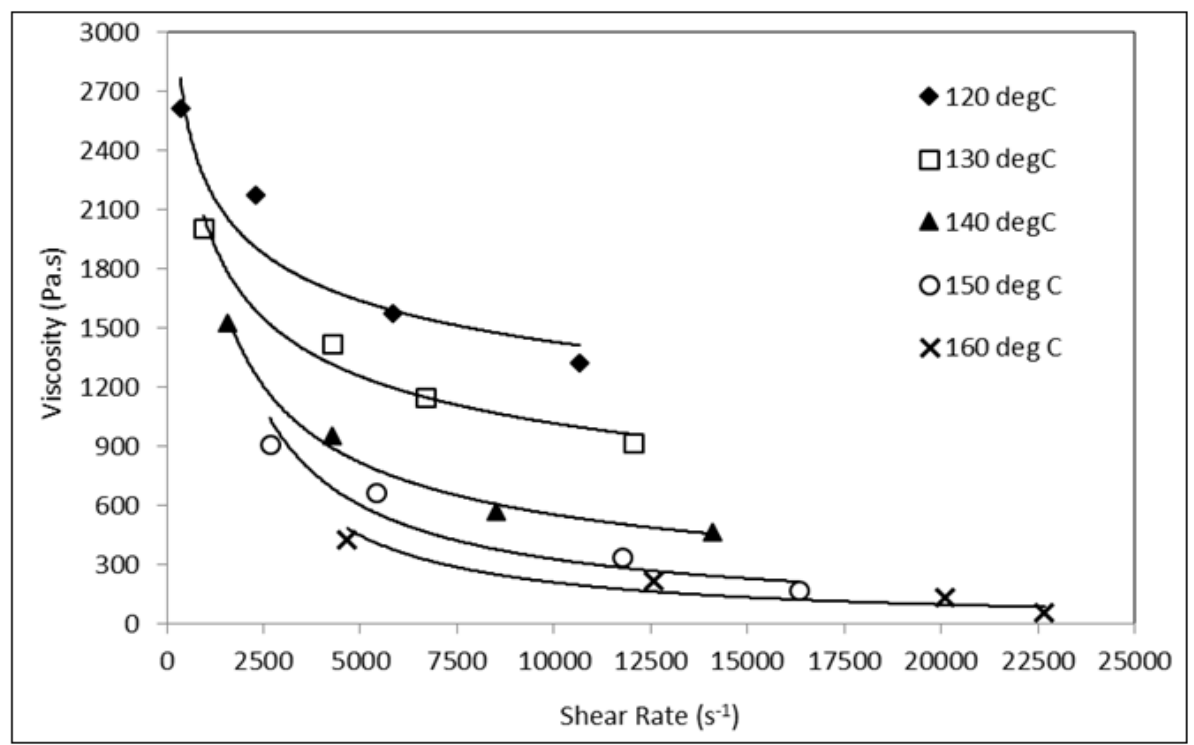

Fig-5: The apparent viscosity versus shear rate of Mg MIM (65 vol. \% powder loading) feedstock at different temperatures

Flow behavior index (n) for $\mathrm{Mg}$ MIM feedstock at different temperature is illustrated in Table-3. The result of $n$ value with effect of different temperature is less than 1 . This indicates that shear stress and shear rate has low sensitivity on temperature, which is suitable for injection molding. Therefore, $\mathrm{Mg}$ MIM feedstock was characterized as pseudoplastic or shear thinning fluid. This behavior is required in 
injection molding process as it has good rheological stability and great pseudoplaticity and promises less or free defect product.

Table-3: Flow behavior index, $n$ at different temperature

\begin{tabular}{|r|r|}
\hline Temperature $\left({ }^{\circ} \mathbf{C}\right)$ & Flow Behaviour Index, $\mathbf{~}$ \\
\hline 120 & 0.084 \\
\hline 130 & 0.696 \\
\hline 140 & 0.440 \\
\hline 150 & 0.129 \\
\hline 160 & 2.085 \\
\hline average & 0.831 \\
\hline
\end{tabular}

The flow behavior index (n) obtained was less than 1. The viscosity ( $\eta$ ) of the magnesium MIM feedstock decreased with increasing shear rate $(\gamma)$. The magnesium MIM feedstock behaves a Bingham fluid since they required the certain amount of stress to initiate the flow due to present of the powder in the feedstocks. The value proves that the Mg MIM feedstock has a good fluidity and can be injection molded. The typical value of shear rates for MIM is encountered at the mold range from 100 to $1000 \mathrm{~s}-1$ and acceptable value for viscosity is in the range of $100-$ $10000 \mathrm{~Pa} . \mathrm{s}$ and most rheological studies were made in this interval.

\section{CONCLUSIONS}

The powder characterization, mixing process and rheological properties of feedstock consisting of magnesium powder mix with polymer binder system has been investigated. The mixing parameters were based on the DSC analysis of binder components. It can be seen that the feedstock with 65 vol.\% of powder loading showed pseudoplastic behaviour which is the desirable in MIM process. The next step is to conduct the injection moulding process on the magnesium feedstock.

\section{REFERENCES}

1. Wolff, M., Schaper, J., Dahms, M., Ebel, T., \& Kainer, K. T. (2014). Magnesium powder injection moulding for biomedical application. Powder Metallurgy, 57, 331-340.

2. Wolff, M., Schaper, J., Suckert, M., Dahms, M., F., F., Ebel, T., \& Klassen, T. (2016). Metal injection molding (MIM) of magnesium and its alloys. Metals, 6(118).

3. Li, N., \& Zheng, Y. (2013). Novel magnesium alloys developed for biomedical application: A review. Journal of Material Science Technology, 29(6), 489-502.

4. German, R. M. (1990). Powder Injection Moulding. Metal Powder Industries Federation, Princeton, New Jersey.

5. German, R. M., \& Bose, A. (1997). Injection Molding of Metals and Ceramic, Metal Powder Industries Federation, Princeton, New Jersey

6. Omar, M. A., Abdullah, N., Ahmad, I. N., \& Nordin, A., \& Wahab, N. (2018). Physical and Mechanical Evaluation of Injection Moulded of 17-4PH Stainless Steel. Saudi J Eng Technol. 3(9):588-592

7. Omar, M. A., \& Ibrahim, R. (2006). Metal Injection Molding: An Advanced Processing Technology. Journal Industrial Technology, 15(1), 11-22.

8. Czerwinski, F. (2008). Magnesium injection molding (pp. 135-145). New York: Springer.

9. German, R. M., \& Kubish, D. (1993). Evaluation of injection molded 17-4 PH stainless steel using water atomized powder. International journal of powder metallurgy (1986), 29(1), 47-62. 